\title{
The Impact of Cognitive Styles on the Speech Act of Apology among Iranian EFL Learners
}

\section{Ashraf Haji Maibodi ${ }^{1 *}$ \& Halimeh Dehghani $^{1}$}

\author{
* Correspondence: \\ amaibodi2014@gmail.com \\ 1. Department of English, Islamic Azad \\ University, Maybod Branch, Yazd, Iran
}

Received: 17 August 2019

Revision: 30 October 2019

Accepted: 5 February 2020

Published online: 20 March 2020

\begin{abstract}
This study explored the effect of cognitive styles of field dependence (FD) and field-independence (FI) on Iranian EFL learners' performance in the speech act of apology. Additionally, the investigation also focused on the effect of these cognitive styles on individual differences (IDs) like proficiency, age, and gender of the participants. To this end, 80 EFL learners, studying at two English language institutes in Maybod, were selected through convenient sampling. This study was conducted in three phases by using a variety of instruments, like Oxford Quick Placement Test (OPT), Group Embedded Figures Test (GEFT), and Multiple Choice Discourse Completion Tasks (MCDCTs). With respect to the GEFT, students were divided into two groups, FD/FI. The MCDCTs were administered to measure students' pragmatic comprehension and restructuring ability of the apology situations. The obtained data were analyzed using SPSS 21 statistical software. The results revealed that FI participants outperformed the FD ones in apology contexts. Individual differences like gender and age had a significant effect on the performance of the participants in both cognitive groups. Although the proficiency level demonstrated some variations, but it did not have any statistically significant impact on the performance of the participants in these two groups. The major pedagogical implication of the present study is that when assessing the interlanguage pragmatics (ILP) of EFL learners, teachers and other teaching administrations should take not only cognitive styles but also individual differences into consideration so that they could adopt and apply teaching methods in line with the learners' various cognitive styles.
\end{abstract}

Keywords: cognitive styles, field independence, field dependence, individual differences, speech act of apology 


\section{Introduction}

Pragmatics, in second language studies, commonly known as interlanguage pragmatics (ILP), refers to the comprehension and production of action by non-native speakers (NNSs) of a language (Kasper \& Rose, 2002). Kasper and Schmidt (1996) believed that, "the focus is given to the ways NNSs' pragmalinguistic and sociopragmatic knowledge differs from that of native speakers (NSs) and among learners with different linguistic and cultural backgrounds" (p.150). In a simple and comprehensive definition, Ishihara and Cohen (2010) defined it as "being able to go beyond the literal meaning of what is said or written, in order to interpret the intended meanings, assumptions, purposes or goals, and the kinds of actions that are being performed" (p.5).

In the area of discourse analysis, speech acts by definition are not only linguistic expressions, but also linguistic actions that carry out communicative purposes. They refer to the acts we perform when we speak: giving reports, giving advice, agreeing, complaining, apologizing and are defined in terms of discourse functions. Under the category of expressives, apology (Afghari, 2007; Bergman \& Kasper, 1993; Dalmau \& Gotor, 2007; Haji Maibodi, 2016; Holmes, 1995; Trosborg, 1995), as one of the main speech acts, is frequently used in human interactions. As a face saving, remedial act of speech, apologies are required when the social norms of politeness demand the mending of a behavior. One of the central research questions in the field of ILP is how learners produce apologies in a second/foreign language and the extent to which their mitigating strategies deviate from or approximate the strategies that native speakers use.

Human beings have their own commonalities and variances, which distinguish them from other creatures in general and from one another in particular. ILP (Kasper \& Rose, 2002; Kasper \& Schmidt, 1996; Kuriscak, 2010; Taguchi, 2013) can be affected by some factors like cognitive styles and individual differences (IDs). Studying the effect of learner characteristics (IDs) like proficiency level (Bardovi-Harlig \& Bastos, 2011; Taguchi, 2013; Takahashi, 2005), gender (Holmes, 2008), and age (Kasper \& Rose, 2002; Marinova-Todd, Marshall, \& Snow, 2000) on L2 learning (Bayat, 2013; Davies \& Skilton-Sylvester, 2004; Taguchi, 2013) is not a new issue. However, the interaction between such factors and pragmatic development has only recently been addressed.

As another area of research in L2 pedagogical contexts, investigations of IDs have led to the determination that there are styles of thinking called cognitive styles. Field Dependency (FD) and Field Independency (FI) is one of the dichotomies of a more broad term "cognitive style" which embraces the "thinking style" and involves the way individuals think, perceive, and remember information. Salmani-Nodoushan (2007) defined these cognitive styles as "the link between personality and cognition that influences how we learn things in general and the particular approach we adopt when dealing with problems" (p.83).

The FD/FI model, invented by Witkin, Moore, Goodenough, and Cox (1977), identified an individual's perceptive behavior while he/she is distinguishing figures from the surrounding field in which the objects are set. That is, a FI learning style is defined as a tendency to separate details from the surrounding context, while a FD learning style is defined as a relative inability to distinguish detail from other information around it. However, the potential effect of these cognitive styles has not been studied broadly in ILP.

\subsection{Statement of the Problem}

Pragmatic competence is considered as one of the most complex and challenging areas for L2 learners as people from different societies and cultures seem to be interacting with greater and greater frequency. L2 learners lack pragmatic knowledge on how to interpret discourse by relating utterances to their meanings, understanding the intention of language users and how language is used in specific settings (Bachman \& Palmer, 2010). In addition, speech acts are difficult to perform in L2 because learners may not know the idiomatic expressions or cultural norms in the second language or they may transfer their first language rules and conventions into the second language, assuming that such rules are universal. Learners' pragmatic behavior tends to be interpreted as manifestation of their character and personality.

In the Iranian English as a Foreign Language (EFL) context, very little attention has been paid to communicative abilities such as pragmatic competence, which includes both receptive and productive skills like ability to understand meaning as intended and to vary one's language use appropriately to the particular sociocultural context. Many EFL students do not have the necessary opportunities to practice English in authentic ways and when language is not practiced outside the classroom, students quite naturally develop limited perceptions of pragmatic knowledge. The problem arises when L2 learners' grammatically accurate but pragmatically inappropriate utterances may be negatively viewed not because of their limited communicative competence but as an indication of their ill intentions or faulty 
personalities. The language classroom is a setting where the target language is taught as a subject only and is not commonly used as a medium of communication outside the classrooms and pragmatic competence is not a high priority (Ellis, 2008).

Unfortunately today, in the Iranian curriculum, all aspects of EFL instruction are limited to linguistic competence like grammar, syntax, and vocabulary, and EFL students in general are not socialized to the target language forms used in social interactions. Iranian EFL student's linguistic behavior reveals that very few of them seem to converge to the target language pragmatic norms of communication (Haji-Maibodi et al., 2016).

The main objective of the present study was to investigate the effect of cognitive styles like FD and FI on the speech act of apology among Iranian EFL learners. Since IDs determine a great deal of what we want to communicate, cognitive styles of EFL students at different proficiency levels, of different ages and gender can also affect their recognition and comprehension of speech act situations. Largely, this study was motivated by the gaps in previous research. Most of the research to date related to the study of cognitive styles in the Iranian EFL context (e.g. Ahmadi, 2002; Biook \& Fathi, 2009; Fatemi, Vahedi, \& Seyyedrezaie, 2014; Hashemian \& Farhang Ju, 2018; Hashemian, Jafarpour, \& Adibpour, 2015; Khodadady, Bagheri, \& Charbgoo, 2016; Khodadady \& Zeynali, 2012; Nilforooshan \& Afghari, 2007; Roostampor \& Niroomand, 2014; Sabet \& Mohammadi, 2013; Salmani-Nodoushan, 2006, 2007; Shalbafan, 1996; Sheorey \& Mokhtari, 2001; Yaghoubi, 1994) to name a few have been limited to acquisition of language skills only. So far, no research in the Iranian EFL context has been exclusively devoted to the study of cognitive styles and pragmatics especially on the effect of FD/FI styles on IDs and the speech act of apology in second language acquisition.

\subsection{Research Questions}

Based on the above perceptions, the following research questions were proposed:

1. Is there any significant difference between FD/FI Iranian EFL learners regarding their pragmatic competence in apology context?

2. Does proficiency level make any difference between FD/FI Iranian EFL learners regarding their pragmatic competence in apology context?

3. Does age make any difference between FD/FI Iranian EFL learners regarding their pragmatic competence in apology context?

4. Does gender make any difference between FD/FI Iranian EFL learners regarding their pragmatic competence in apology context?

\subsection{Research Hypotheses}

The hypotheses of this study are as follows:

$\mathrm{H}_{1}$ : There is no significant difference between FD/FI Iranian EFL learners regarding their pragmatic competence in apology context.

$\mathrm{H}_{2}$ : Proficiency level does not make any difference between FD/FI Iranian EFL learners regarding their pragmatic competence in apology context.

$\mathrm{H}_{3}$ : Age does not make any difference between FD/FI Iranian EFL learners regarding their pragmatic competence in apology context.

$\mathrm{H}_{4}$ : Gender does not make any difference between FD/FI Iranian EFL learners regarding their pragmatic competence in apology context.

\section{Review of the Literature}

\subsection{Cognitive Styles}

In the field of information processing, cognitive styles have emerged as a new dimension within IDs through cognitive psychology studies. It has a particular importance as it determines the way information is processed when solving problems or making decisions or interpretation of stimuli and response (Hansen, 1981). Students with different types of cognitive styles may have challenges in various aspects of language learning and, therefore, they may need different 
instructional strategies to suit their information processing needs and preferences (Luk, 2002). FD/FI can be considered as one of these cognitive styles that may affect language learning (Fajen, 1999). FD is defined as a cognitive style in which a person looks at the whole of a learning task that contains many items. These learners may have problems studying a specific item as a part of the whole. They have a personal orientation to their environment, are more holistic and dependent i.e., their self-view is derived from others. In interpersonal and social interactions they are less skilled and not so socially aware (Reid, 2002). On the other hand, FI is defined as a cognitive style in which the learner can identify or focus on particular items, and is not distracted by other items in the background or context (Brown, 2007). Reid (2002) believed that such individuals are more analytic, socially sensitive, and independent. In processing information they have a strong reliance on their own internal frame of reference.

An important question for language researchers is the effect of cognitive styles on the efficacy of language learning. Carroll and Sapon (1988) were the first applied linguists who showed FI is significantly related to foreign language aptitude, as measured by the Modern Language Aptitude Test. Griffin and Franklins (1996) indicated that FI students performed significantly better on course tests and suggested that these students had higher academic potential than their FD counterparts did. Fajen (1999) conducted two experiments on listening and reading, concerning FD/FI cognitive styles. Results showed that FI participants seemed to use a tacit structure strategy, whereas FD participants appeared to display structuring skills while note taking. Tinajero and Paramo (1997) investigated the relationship between cognitive styles and student achievement in several subject domains (English, mathematics, natural science, social science, Spanish, and Galician). Results showed that FI subjects outperformed their FD counterparts. Luk (2002) reported in two studies the relationship between FD and academic learning in the context of distance learning with Bachelor of Health nursing students in Hong Kong. In both studies FI nurses performed significantly better than FD ones.

In the Iranian EFL context, Yaghoubi (1994) conducted a pioneering research to examine to what extent there was a relationship between FD/FI cognitive styles and foreign language proficiency of Iranian EFL students. Findings revealed that FI learners outperformed FD ones in language classes and language learning. Shalbafan (1996) investigated whether the findings of earlier researches on the relation between FD/FI and EFL learners' achievement could be extrapolated to Iranian EFL learners' writing ability. Sheorey and Mokhtari (2001) studied the relationship between FD/FI cognitive style and performance on global and local questions in listening comprehension. He concluded that there was no relationship between FD/FI and the students' performance on global questions. However, FI students answered local questions better than their FD counterparts did. On the other hand, Salmani-Nodoushan (2006) provided evidence that FD subjects, compared to their FI counterparts, performed much better on communicative tests and concluded that test takers' cognitive styles may be viewed as a source of systematic variance in test performance. Salmani-Nodoushan (2007) also examined the relationship between FD/FI on EFL reading performance. He found that FD individuals outperformed FI participants on tasks that required holistic skills, whereas FI participants outperformed FD participants on tasks that required analytic skills.

Nilforooshan and Afghari (2007) in exploring the effect of FI/FD on second language writing performance concluded that the potential sources of difference between the performances of FD/FI may be attributable to the difference between the kind of reasoning in the two groups, their restructuring ability, use of strategies in processing information and in writing process, and memory retrieval. Biook and Fathi (2009) also found that their 30 intermediate level FI learners outperformed their $30 \mathrm{FD}$ counterparts on a reading comprehension test.

Khodadady and Zenali (2012) studied the relationship between FD/FI cognitive style and listening comprehension ability. The results of this study showed that FI participants outperformed FD participants in IELTS listening comprehension and all of the listening tasks. However, they found that FD cognitive styles compared to FI correlates more significantly with multiple choice and matching questions compared to FI cognitive style.

Khalili Sabet and Mohammadi (2013) investigated the relationship between FD/FI styles and reading comprehension abilities of intermediate EFL readers. The results of the quantitative analysis of the data via t-test revealed that FD participants treated the reading text as a whole while their FI counterparts focused only on the covert message and parts of the reading text. Fatemi, Vahedi, and Seyyedrezaie (2014) aimed at the effect of top-down/bottom-up processing and FD/FI cognitive style on Iranian EFL learners' reading comprehension. Apparently, FI learners in the bottom-up group outperformed their FD counterparts. However, FD learners were more successful than FI ones when taught through top-down reading instruction model. 
Considering FD/FI cognitive styles, Rostampour and Niroomand (2014) aimed at determining if they are significant in English vocabulary knowledge. Additionally, Hashemian, Jafarpour, and Adibpour (2015) studied the relationships between FI, multiple intelligences, and L2 reading performance among Iranian L2 learners. Results revealed significant positive relationships between FI and performance on the four reading tasks of true-false, sentence completion, outlining, and scanning. Khodadady, Bagheri, and Charbgoo (2016) explored the relationship between cognitive styles and achievement in EFL. The independent samples $t$-test showed that the FI primary school students' EFL achievement was significantly higher than their FD counterparts were. Hashemian and Farhang-Ju (2018) examined the possible effects of metalinguistic feedback on FI/FD intermediate L2 learners' writing accuracy. Although the results revealed that both the FI/FD learners benefited from metalinguistic feedback, the FD participants outperformed the FI ones.

As it is revealed from the literature review, most of the studies concerned with cognitive styles are limited in their investigations to language skills and those exploring the effect of cognitive styles on pragmatic competence is really ignorable. Therefore, there is a great need to work on the effect of cognitive style and individual differences on pragmatic competence.

\section{Methodology}

\subsection{Design of the Study}

The primary purpose of the current investigation was to determine the effect of FI/FID cognitive styles on the speech act of apology among Iranian EFL learners. Furthermore, the purpose of this study was also to explore to what extent individual differences of gender, age, and students' proficiency level together with cognitive styles of FID and FD can have a significant effect on the speech act of apology among Iranian EFL learners. Therefore, the independent variables of the study were field dependent and independent cognitive styles and three individual differences of age, gender, and proficiency level. Moreover, the participants' scores on the recognition and comprehension apology situations were considered as the dependent variables. To this aim, all data gathered were numerical and objective. This study was conducted in three phases. The pool of obtained data was analyzed using SPSS (statistical package for social sciences) software. The detailed statistical analyses, conducted for fulfilling each objective, are presented below.

\subsection{Participants}

The participants were selected from 150 Persian speaking EFL learners of advanced levels at two English Language Institutes in Maybod, Yazd. Due to institutional constraints, convenient sampling was used. The advantages of this type of sampling are the availability and the quickness with which data can be gathered. Both males and females were included and their ages ranged from 17 to 34 years. Students at these language institutes were already divided according to the placement test administered by the institutes. The Oxford Placement Test (OPT) was administered to establish the proficiency level and 80 students were selected. This study as part of a larger project was piloted to evaluate the appropriateness of the assessment instruments. Four upper-intermediate and four advanced students from the two institutes who shared the same learning conditions participated in the pilot study. The participants went through the process of interacting with the assessment materials, and completing the modified GEFT (although the validity is internationally proven, but it was piloted to check it for Iranian EFL learners) test and the MCDCTs. Feedback and suggestions were used to improve the design of the final study.

\subsection{Instruments}

The instruments for this study were selected according to the research questions set for this study. At the outset, it must be mentioned that there was no intention of overloading the students with too many tests at one particular time that would definitely be tiring and strenuous. In order to accomplish the purposes of this study, the following three tests were administered.

\subsubsection{Oxford Placement Test (OPT)}

The OPT consists of 60 items, each with three alternatives from which the test takers choose the correct response. According to the guidelines provided by the test designers, EFL learners scoring from 45 to 60 are taken as advanced and those students whose scores were 30 to 45 were selected as the upper-intermediate students. Therefore, forty students as upper-intermediate and forty others as advanced participants were selected for this study. It is worth mentioning that 43 students got a score higher than 45 , but in order to have equal number of participants in each proficiency group, only 40 EFL learners were chosen. Moreover, the same participants were divided into three age groups (17-22, 23-28, \& 29-34). These two groups were also subdivided according to gender. 


\subsubsection{Group Embedded Figures Test (GEFT)}

The Group Embedded Figures Test (GEFT) is used for determining FD/FI cognitive styles of the participants. The GEFT (Oltman, Raskin, \& Witkin, 1971 as cited in Bosacki, Innerd, \& Towson, 1997) is a group-administered test that requires the subject to outline a simple geometric shape within a complex design. According to this test, the subjects were given a booklet with simple visual figures embedded inside progressively more complicated visual figures. The subjects were expected to locate the hidden simple form or figure in the more complex one within a given time (12 minutes). It was supposed that those who tend to rely on external cues are less able to find the simple figures so are FD, and those who rely on internal cues are more able to find figures, hence, FI. There are 25 complex figures in the GEFT, each with an embedded simple figure. Based on the number of correct answers given by students, the scores on GEFT may range from 0 (the most FD) to 18 (the most FI). The GEFT includes 20 items. The reliability score calculated for the present study was $\alpha=0$. 91. In this study, the modified version of GEFT was used.

Based on the obtained scores on the GEFT, EFL learners were divided to two groups of FD and FI cognitive styles. Each participant's score in the modified GEFT is obtained by adding the total number of correctly answered items. In the current study, participants whose scores ranged from 0-14.5 were classified as FD learners and participants whose scores ranged from 14.5-20 were classified as FI learners (14.5 is the median GEFT score of the subjects as stated by Salmani-Nodoushan, 2007).

\subsubsection{Multiple Choice Discourse Completion Task (MCDCTs)}

Ten apology situations were administered. Each situation had one stem and four responses. In the MCDCTs, distractors are not always incorrect, as they are on a grammar test. They were rated on the degree of appropriateness in the specified situation. That is, the key was based on the option that was the most appropriate both pragmatically and linguistically in the designated situation (Farhady, 1980 as cited in Liu, 2004). However, it must be noted that in pragmatics, there are no absolutely appropriate or inappropriate response. The speech act situations of apology were administered with the aim of investigating participants' ability to comprehend and recognize the speech act situations. The reliability of this was approved by conducting Cronbach alpha analysis $(\alpha=0$. 77). The MC format is still the main test method used in Iran and in high-stakes tests such as the National Entrance Exams held for entrance to universities. The MCDCTs for this study were adapted from Birjandi and Rezaii (2010) and Haji Maibodi (2016).

\subsection{Data Collection Methods}

This study was conducted in three phases. In the first phase, 150 Persian speaking EFL candidates from two English language institutes in Maybod, were selected to participate in this study. Demographic survey questionnaire was employed to gain information about the learners' gender, age, and learning experience. Both males and females were included and 54 females and 26 male EFL learners participated in this study. The age range of the participants was between 17 and 34 years. They were divided into three groups. 43 participants were 17 to 22 years. 21 EFL learners were 23 to 28 years old. Finally, the rest of the participants included in the group were between 29 to 34 years old. Then, in order to establish the participants' proficiency level, the OPT was administered. Based on the scores obtained on the test, only those students whose scores were at upper-intermediate and advanced level were taken into consideration. Finally, a total number of 80 participants were found eligible for this study. Thus, forty participants were taken to be upper-intermediate and the other 40 students were considered advanced.

In the second phase, the students' degree of FD/FI was determined by the modified version Group Embedded Figures Test (GEFT). GEFT is globally used for FD/FI cognitive styles determination. In the third phase after students were divided according to age, proficiency level, and cognitive styles, the MCDCTs were administered. Participants were told to provide responses that they think are appropriate for the given context and situation. The focus on the speech act section was on the assessment of participants' knowledge of pragmatic strategies, their linguistic implementation, and the appropriateness of language use. For the MCDCTs, ten apology situations were administered. Guidelines as to how to answer the test were given to the participants. Each apology situation had one stem with four responses. One response was the appropriate one and the three other inappropriate ones were taken as distracters for each scenario.

In MCDCTs, distracters are not always incorrect, as they are on a grammar test. They are rated on the degree of appropriateness in the specified situation. The situations were culturally appropriate and salient to the students. The participants had to choose the most appropriate option among the four choices that accompany the stem (see Appendix). No doubt, modifications were made to make the format more like a face-to-face interaction. When, all the test items were administered, the researchers scored them. Of course, sample papers were provided to the supervisor 
for further checking. Finally, the raw data were provided to the statistical analyst. Since the number of the participants of the age and gender groups was not equal, first, the analyst conducted some normalization and equalization processes. Finally, the main statistical analyses were conducted.

\subsection{Data Analysis Procedures}

The collected data were fed into SPSS 20. It is worth mentioning that all incomplete surveys were discarded from the analysis. First, descriptive and frequency analyses were conducted. Then, based on these results the comparative statistical procedures were administered. Because the students were divided to three age groups, a one-way between groups ANOVA was conducted. However, considering proficiency level and gender, since the students were divided into two groups, independent-samples t-tests were undertaken.

\section{Results}

\subsection{Order of Test Administration}

Initially, the Oxford Placement Test (OPT) was administered to evaluate the proficiency levels of the participants in the three groups. Students were assured that this proficiency test was to tap their overall English knowledge and as such did not have any negative points. Explanations about the test were given orally in Persian (students' L1). This test was administered with a focus on structure and vocabulary in two formats-one in the form of five cloze tests and the other in a multiple-choice format. The total number of items was about 60 items and the test was divided into two parts. Part 1 had questions from 1-40 and part two from 41-60. The time allotted was 30 minutes. The students' scores on the OPT was based according to the standards (proficiency levels) set by the test itself. Those scores that ranged between 30 and 45 were regarded as upper intermediate and those scores that were more than 45 were labeled as advanced. Participants were also divided according to other individual differences such as age range and gender. The following table represents the division of the participants according to their individual differences.

Table 1. Background information of the participants $(\mathrm{N}=80)$

\begin{tabular}{llllll}
\hline Group & $\mathrm{N}$ & Male & Female & Age & Proficiency score \\
\hline Upper-intermediate & 40 & 17 & 23 & $17-34$ & $30-45$ \\
Advanced & 40 & 9 & 31 & $17-34$ & $45-60$ \\
\hline
\end{tabular}

\subsection{Analyses for Research Objectives Concerning Individual Differences}

The first objective of the present study was concerned with the difference in the mean test scores for FD and FI individuals. Therefore, an independent-samples $t$-test was conducted to compare the overall apology MDCTs scores for FD and FI individuals. Table 2 represents the descriptive statistics on the performances of each group of cognitive style.

Table 2. Descriptive results on the performances of FD and FI individuals in apology MDCTs

\begin{tabular}{llllll}
\hline & Field dependence & $\mathrm{N}$ & Mean & Std. Deviation & Std. Error Mean \\
\hline Apology & FD & 31 & 8.5000 & 3.23443 & .51141 \\
DCT & FI & 49 & 11.750 & 3.54278 & .56016 \\
\hline
\end{tabular}

In response to research question 1, the findings of Table 2 show that the mean scores of FD $(M=8.50, S D=3.23)$ and FI $(M=11.750, S D=3.54)$ participants were not the same. However, the difference between these two scores needed to be approved statistically. Table 3 provides the statistical numbers obtained by conducting an independent sample t-test in order to compare FD and FI individuals. 
Table 3. Independent Samples T-Test on the performances of FD and FI individuals in apology MDCTs

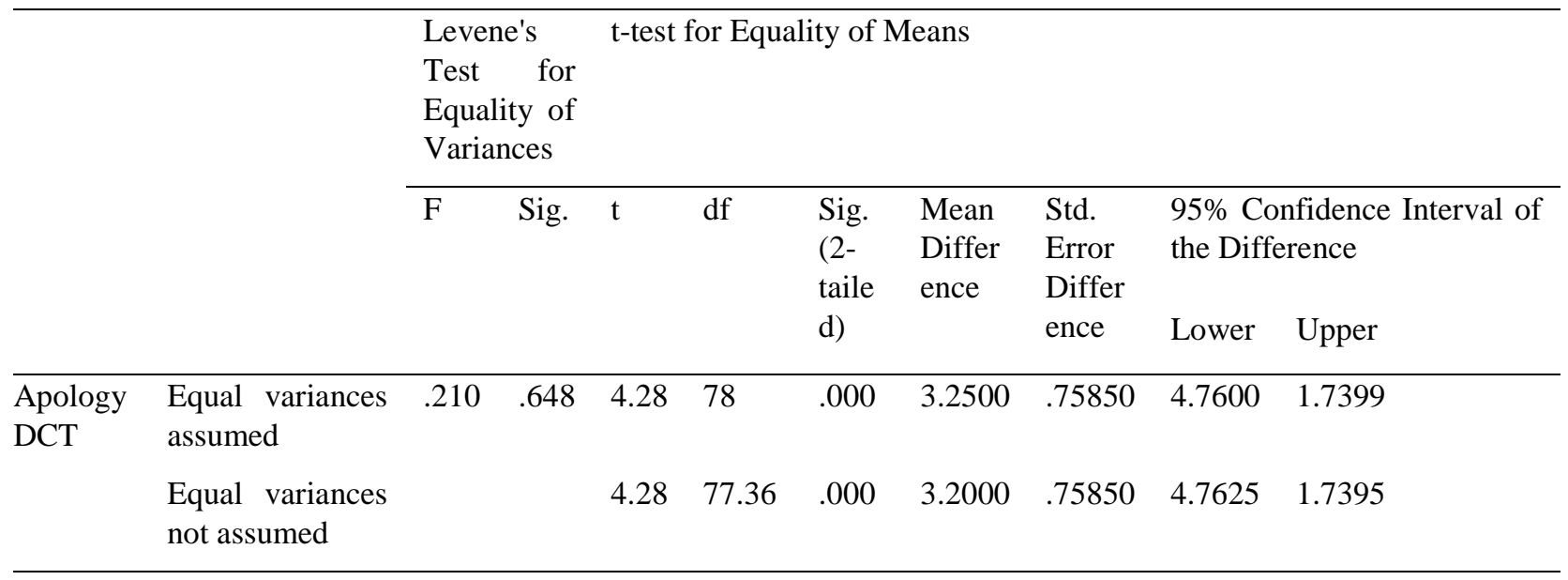

According to the numerical findings of Table 3, there was a significant difference between the test scores of FD $(M=8.50, S D=3.23)$ and FI $(M=11.750, S D=3.54)$ participants; $t(78)=4.28, p=.0 .000)$. The magnitude of the difference in the means was very large (Eta squared=0.86).

The second objective of the current study was concerned with the difference in the mean test scores for FD and FI individuals within different proficiency groups. Therefore, two independent-samples $t$-test were conducted to compare the overall apology MDCTs scores for FD and FI individuals. Table 4 represents the descriptive statistics on the performances of each group.

Table 4. Descriptive results on the performances of FD and FI individuals in apology MDCTs regarding their proficiency level

\begin{tabular}{|c|c|c|c|c|c|}
\hline $\begin{array}{l}\text { Cognitive } \\
\text { Style }\end{array}$ & Proficiency & $\mathrm{N}$ & Mean & SD & Std. Error of Mean \\
\hline \multirow{2}{*}{ FD } & Upper-intermediate & 20 & 8.200 & 3.2379 & 0.7240 \\
\hline & Advanced & 20 & 8.800 & 3.2863 & 0.7346 \\
\hline \multirow{2}{*}{ FI } & Upper-intermediate & 20 & 11.400 & 3.8443 & 0.8596 \\
\hline & Advanced & 20 & 12.100 & 3.2751 & 0.7328 \\
\hline
\end{tabular}

The results of Table 4 show that upper-intermediate $(\mathrm{M}=8.20, \mathrm{SD}=3.23)$ and advanced $(\mathrm{M}=8.80, \mathrm{SD}=3.28)$ participants in FD group had similar performances in apology MDCTs. In the same vein, FI upper-intermediate (M = $11.40, \mathrm{SD}=3.84)$ and advanced $(\mathrm{M}=12.10, \mathrm{SD}=3.27)$ groups had also similar performances in apology contexts. The significance of the difference between these proficiency levels was explored conducting two independent samples t-tests. Table 5 provides the statistical numbers obtained by conducting independent samples $t$-test in order to compare the proficiency levels of FD and FI individuals. 
Table 5. Independent samples t-test on the performances of FD and FI individuals in apology MDCTs regarding their proficiency level

\begin{tabular}{lllll}
\hline Cognitive Style & $\mathrm{T}$ & df & $\begin{array}{l}\text { sig.(2- } \\
\text { tailed) }\end{array}$ & Eta squared \\
\hline FD & -0.582 & 38 & 0.564 & 0.039 \\
FI & -0.620 & 38 & 0.639 & 0.042 \\
\hline
\end{tabular}

According to the numerical findings of Tables 4 and 5, there was no significant difference between the test scores of FD participants in upper-intermediate $(M=8.20, S D=3.23)$ and advanced $(M=8.80, S D=3.28 ; t(38)=0.582, p=.564)$ groups. The magnitude of the difference in the means was very small (Eta squared=.039). Similarly, the results obtained for the FI participants revealed that there was no significant difference between the scores of upperintermediate participants $(M=11.40, S D=3.84)$ and advanced participants $(M=12.10, S D=3.27 ; t(38)=620, p=.639)$. The magnitude of the difference in the means was small (Eta squared=.042). Therefore, proficiency level did not have any significant effect on the performance of FD and FI participants in apology MDCTs. Table 6 and Figure 1 reveal the statistical findings.

Table 6. Independent samples t-test on the performances of proficiency groups in apology MDCTs

\begin{tabular}{lllll}
\hline Proficiency & $\mathrm{T}$ & $\mathrm{df}$ & sig.(2-tailed) & Eta squared \\
\hline Upper-intermediate & -2.847 & 38 & 0.007 & 0.074 \\
Advanced & -3.181 & 38 & 0.003 & 0.087 \\
\hline
\end{tabular}

The results revealed that as for the upper-intermediate participants, there was a significant difference in scores for FD participants $(M=8.20, S D=3.23)$ and FI participants $(M=11.40, S D=3.84 ; t(38)=2.84, p=.007)$. The magnitude of the difference in the means was estimated and the results revealed to be moderate (Eta squared=.074). The guidelines (proposed by Cohen, 1988) for interpreting Eta squared values are $0.01=$ small effect, $0.06=$ moderate effect, and 0.14 = large effect. Similarly, the results obtained for the advanced group revealed that there was a significant difference between the scores of FD participants $(M=8.80, S D=3.28)$ and FI participants $(M=12.10, S D=3.27 ; t(38)$ $=3.18, p=.003$ ). The magnitude of the difference in the means was moderate (Eta squared=.087). 


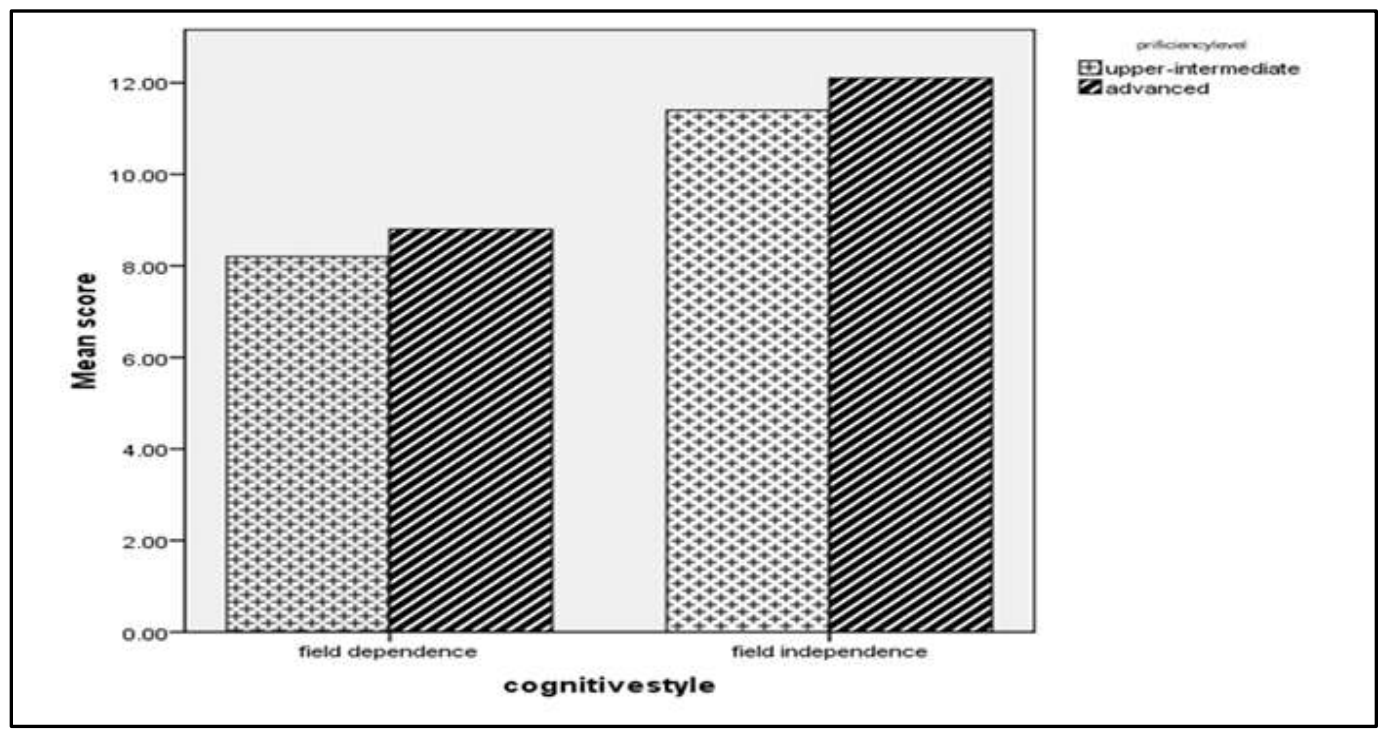

Figure 1. Performance of the participants of FD and FI cognitive style across proficiency levels

The bars of figure 1 show that upper-intermediate and advanced participants in FD group had similar performances in apology MDCTs. In the same vein, FI upper-intermediate and advanced groups had also similar performances in apology MDCTs.

The third research question was whether there was a significant difference in the mean scores of FD and FI individuals in three different age ranges. Regarding the participants' age, they were divided into three groups. 43 participants were aged from 17 to 22 years. Besides, 21 EFL learners were from 23 to 28 years old. Finally, the rest of the participants were included in the group who were from 29 to 34 years old. Therefore, two one-way between groups ANOVA was conducted to compare the apology MDCTs scores of FD and FI individuals in each age group. The descriptive results are represented in Table 7.

Table 7. Descriptive results on the performances of FD and FI individuals in apology MDCTs regarding their Age Group

\begin{tabular}{llllll}
\hline Cognitive Style & $\begin{array}{l}\text { Age } \\
\text { Group }\end{array}$ & N & Mean & SD & Std. Error of Mean \\
\hline \multirow{2}{*}{ FD } & $17-22$ & 16 & 7.333 & 4.3817 & 0.7196 \\
& $23-28$ & 11 & 5.400 & 4.7680 & 0.7546 \\
& $29-34$ & 4 & 10.830 & 4.9841 & 0.7492 \\
FI & $17-22$ & 11 & 8.460 & 4.4829 & 0.7134 \\
& $23-28$ & 20 & 9.933 & 4.5712 & 0.7328 \\
\hline
\end{tabular}

Based on the results of Table 7, the participants in FD and FI groups gained various mean scores in apology MDCTs. Concerning the FD participants, the lowest mean score was observed in 23-28 group $(M=5.40, S D=4.76)$, while 17-22 group $(M=7.33, S D=4.38)$ and 29-34 group $(M=10.83, S D=4.98)$ gained higher scores. On the other hand, regarding the FI participants, the lowest mean score was observed in $17-22$ group $(M=8.46, S D=4.48)$, while 23 -28 group 
$(M=9.93, S D=4.57)$ and 29-34 group $(M=13.28, S D=4.92)$ gained better scores. Table 8 represents the statistical significance of difference between the mean scores of each cognitive group.

Table 8. One-Way between group ANOVA on the performances of FD and FI individuals in apology MDCTs regarding their age group

\begin{tabular}{lllll}
\hline Cognitive Style & F & df & sig. (2-tailed) & Eta Squared \\
\hline FD & 4.376 & $7 / 247$ & 0.010 & 0.04 \\
FI & 5.912 & $7 / 391$ & 0.000 & 0.06 \\
\hline
\end{tabular}

The above-mentioned results indicate that there was a significant difference between different age groups of FDs and FIs. In the case of FD participants, a statistically significant difference was observed in the apology scores of three age groups, $\mathrm{F}(7,247)=4.376, \mathrm{P}=0.010$. Despite reaching statistical significance, the actual difference in mean scores between the groups was not large. The effect size calculated, using eta squared, was 0.073. Similarly, the findings obtained by the analysis of the apology scores of FI participants revealed that there was a statistically significant difference between three age groups, $\mathrm{F}(7,391)=5.912, \mathrm{P}=0.000$. The same as the differences in FD groups, the effect size calculated, using eta squared, was moderate (0.091).

Moreover, post-hoc comparisons using the Tukey HSD test indicated that the mean score of FD group 3 (M = 10.83, $\mathrm{SD}=4.98)$ was significantly different from group $2(\mathrm{M}=5.40, \mathrm{SD}=4.76)$ and group $1(\mathrm{M}=7.33, \mathrm{SD}=4.38)$. Considering FI participants, it was revealed that the mean score of group $3(\mathrm{M}=13.28, \mathrm{SD}=4.92)$ was significantly different from group $1(\mathrm{M}=9.93, \mathrm{SD}=4.57)$ and group $2(\mathrm{M}=13.28, \mathrm{SD}=4.92)$. However, in order to determine the effect of field dependency on different age groups, an independent samples t-test was conducted.

Table 9. Independent samples t-test on the effect of cognitive styles on different age groups on apology MDCT

\begin{tabular}{lccccc}
\hline Age Group & $\mathrm{T}$ & $\mathrm{df}$ & $\begin{array}{l}\text { sig. (2- } \\
\text { tailed) }\end{array}$ & Eta Squared \\
\hline $17-22$ & -0.817 & 71 & 0.639 & 0.019 \\
$23-28$ & -0.391 & 71 & 0.612 & 0.027 \\
$29-34$ & -0.520 & 71 & 0.473 & 0.011 \\
\hline
\end{tabular}

The findings of Table 9 demonstrate that field dependency did not have any significant effect on the performance of the same age group. Total performance of three age groups of FD and FI cognitive styles in apology MDCTs is visually presented in figure 2 . 


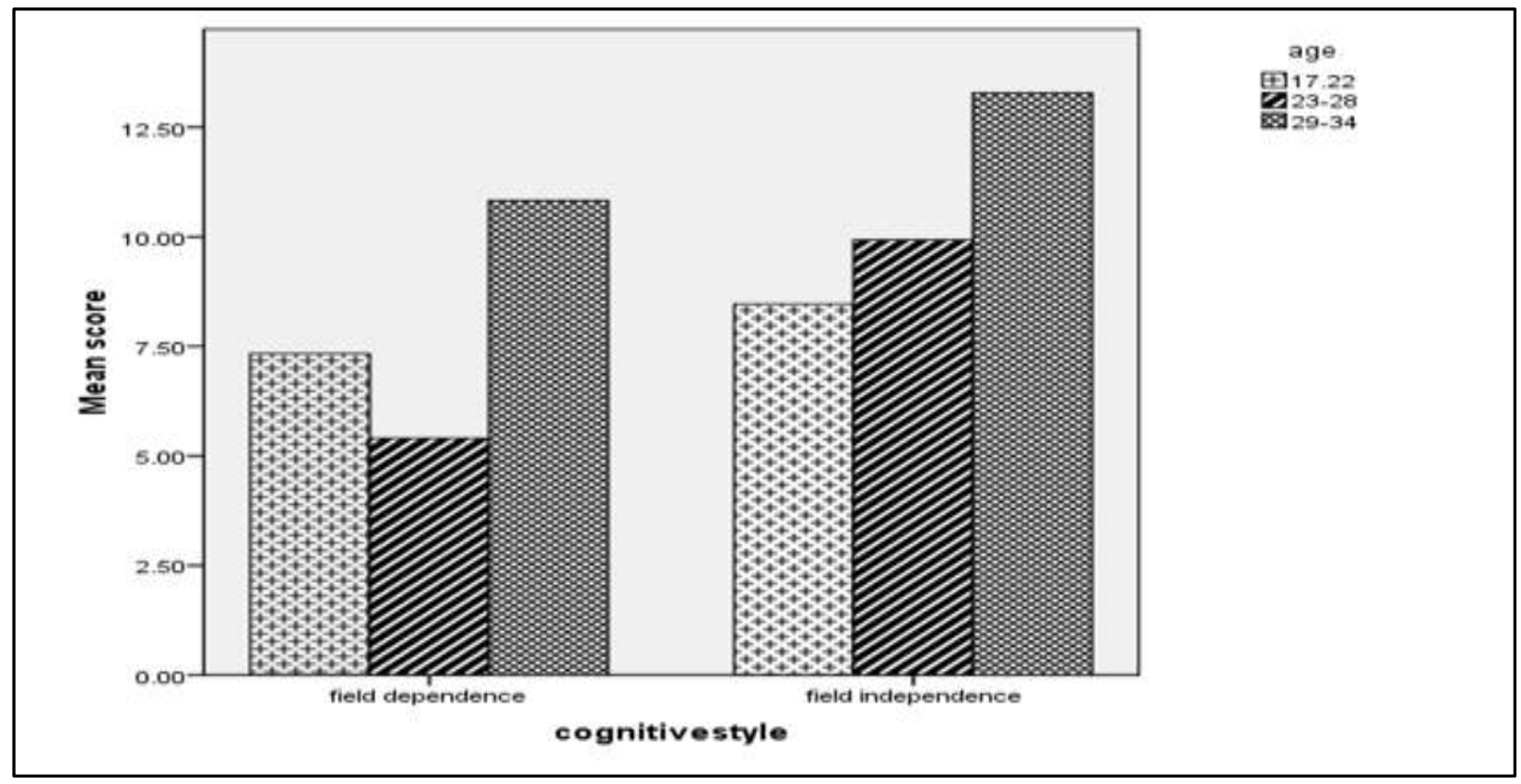

Figure 2. Performance of the participants of FD and FI cognitive style across age groups

As it is apparent in this bar graph, the bars are in line with the findings obtained in the above mentioned tables. The field independent participants, in 17-22 and 29-34 groups, had better performance compared to the ones in the field dependent group. However, the ones in 23-28 showed a reverse performance. The last objective of the present study was concerned with the difference in the apology MDCTs mean scores of FD and FI male and female participants. Therefore, two independent samples t-tests were conducted to compare the apology MDCTs scores for FD and FI men and women. The descriptive and analytic results are represented in Tables 10 and 11.

Table 10. Descriptive results on the performances of FD and FI individuals in apology MDCTs regarding their gender

\begin{tabular}{llllll}
\hline Cognitive Style & Gender & $\mathrm{N}$ & Mean & SD & Std. Error of Mean \\
\hline \multirow{2}{*}{ FD } & Male & 12 & 6.480 & 4.0319 & 0.5927 \\
& Female & 19 & 10.520 & 5.7912 & 0.7611 \\
\multirow{2}{*}{ FID } & Male & 19 & 10.500 & 5.6036 & 0.6049 \\
& Female & 35 & 13.000 & 5.1610 & 0.6359 \\
\hline
\end{tabular}

According to the numerical findings of Table 10, there was a significant difference between the test scores of FD participants in male $(M=6.48, S D=4.03)$ and female $(M=10.52, S D=5.79), t(45)=0.2 .13, p=0.000)$ groups. The magnitude of the difference in the means was moderate (Eta squared=.098). Similarly, the results obtained for the FI participants revealed that there was a significant difference between the scores of male participants $(M=10.50$, $S D=5.603)$ and female participants $(M=13.00, S D=5.16) ; t(45)=2.048, p=0.000)$. The magnitude of the difference in the means was moderate (Eta squared=.072). Therefore, gender had a significant effect on the performance of FD and FI participants in apology MDCTs. The significance of the difference between these genders was explored conducting two independent samples t-tests. Tables 11 and 12 represent the related results. 
Table 11. Independent samples t-test on the performances of FD and FI individuals in apology MDCTs regarding their gender

\begin{tabular}{lllll}
\hline Cognitive Style & T & df & $\begin{array}{l}\text { sig. }(2- \\
\text { tailed })\end{array}$ & Eta squared \\
\hline FD & -2.138 & 45 & 0.000 & 0.098 \\
FID & -2.048 & 45 & 0.000 & 0.072 \\
\hline
\end{tabular}

Table 12. Independent samples t-test on the effect of cognitive styles of different genders on apology MDCTs

\begin{tabular}{llllll}
\hline Gender & $\mathrm{T}$ & $\mathrm{df}$ & $\begin{array}{l}\text { sig. } \\
\text { tailed })\end{array}$ & $(2-$ & Eta Squared \\
\hline Male & -3.817 & 45 & 0.000 & 0.011 \\
Female & -3.391 & 45 & 0.000 & 0.090 \\
\hline
\end{tabular}

According to the numerical findings of Table 12, FD/FI cognitive styles had a significant effect on the performance of male $(t(45)=3.81, P=0.000)$ and female $t(45)=3.39, P=0.000)$ groups. Total performance of male and female participants in apology MDCTs is illustrated visually in figure 3. As it is apparent, the bars, in this bar graph, confirm the findings obtained in the above mentioned tables.

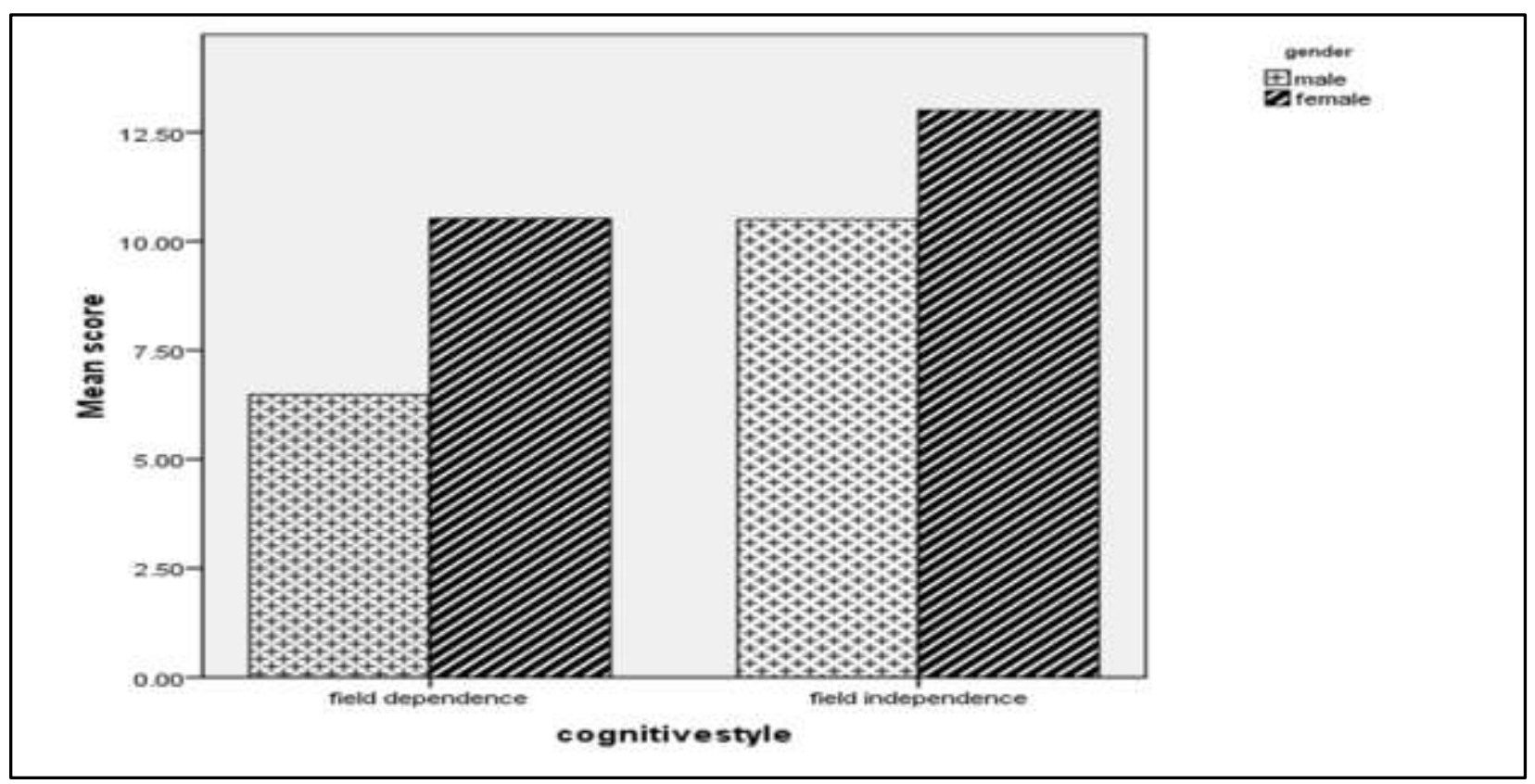

Figure 3. Performance of the participants of FD and FI cognitive style regarding gender

The bars, in this bar graph, confirm the findings obtained in the above mentioned tables. The male participants performed poorly in apology conditions, compared to their female counterparts. 


\section{Discussion}

The major aim of this study was to investigate to what extent cognitive styles of FD/FI and IDs can influence the comprehension and recognition of speech act situations of apology. For measuring IDs the focus was only on proficiency, age, and gender. Based on the conventional assumption that acquiring native like pragmatic competence is the goal of all learners, investigations also explored L2 speakers' pragmatic L2 use in relation to their IDs. No doubt, it is worth mentioning that the related literature stated for the current study were all primarily based on the students' acquisition of language skills. Since no established literature was found on pragmatic competence, the researchers tried to find positive links with the literature reviews mentioned in this study in order to find similarities and differences as far as reading comprehension and vocabulary competence of the apology situations. Moreover, prior to this study, the participants did not have any special training regarding pragmatics, or speech acts. The test items given to the students were in the form of MCDCTs to measure their pragmatic comprehension of the apology situations (see Appendix).

The first research question of this study was concerned with the difference between cognitive styles of FD/FI of Iranian EFL learners and their pragmatic competence in apology contexts. Findings of Table 3 showed that, there was a significant difference between the test scores of FD $(M=8.50, S D=3.23)$ and FI $(M=11.750, S D=3.54)$ participants, $t$ $(78)=4.28, p=.0 .000)$ and FI participants outperformed the FD group. In line with the findings of Yaghoubi (1994), Salmanian (2001), Luk (2002), Biook and Fathi (2009), Sabet and Mohammadi (2013), Rostampour and Niroomand (2014), Fatemi et al. (2014), Hashemian et al. (2015), and Khodadady et al. (2016), the results of this study also revealed significant differences between FI students' performance as compared to their FD counterparts. As Ahmadi (2002) concluded, our results also showed that FI students tend to use metacognitive strategies, which involve monitoring, planning, and organization, more frequently than their FD counterparts do.

Even, Nilforooshan and Afghari (2007) in their attempt to study the impact of FD/FI on EFL learners' writing performance found that the difference between the two groups could be attributed in the kind of reasoning, the way they understood the apology situations and the strategies they used to process information. However, this study was not restricted to only how the EFL learner is capable of using the language to get things done but also focused on their choice of linguistic expressions to use the speech act to maintain interpersonal relationships. Yet, the number of studies working on the effect of cognitive styles on language learning, especially pragmatics and speech acts is unavailable. Therefore, this study can be considered as an innovative work that has uncovered many gaps in this area. As Rickards, Fajen, Sullivan, and Gillespie (1997) mentioned, FI is associated with the ability to detect "the important content of a text and its underlying structure" (p.509). That is, FI involves structuring skills, which affect performance on a wide range of perceptual and cognitive tasks. As already mentioned, the MCDCTs were administered to measure the students' degree of comprehension and recognition of the apology situations and how they categorize their experiences.

However, our results were contrary to Salmani-Nodoushan $(2006,2007)$ whose studies based on cognitive styles found that FD individuals as, compared to FI ones, performed much better. In the same line, Khodady and Zenali's (2012) investigations on listening comprehension found that FD cognitive style comparatively outperformed FI students more significantly with multiple choice and matching questions. Hashemian and Farhan-Ju (2018) reported that both the FI/FD participants benefited from metalinguistic feedback, whereas the FI/FD participants' writing grammatical accuracy assigned into the control group did not improve over time. Witkin et al. (1977) argued that the FI/FD cognitive styles now seem best conceived as tendencies to function with greater or less autonomy of external referents, manifested in both the cognitive and social domains.

In response to research question two, the proficiency levels of the two groups were compared. As far as their cognitive styles were concerned, no significant difference in their performance was observed. The results of Table 4 show that FD individuals in the upper-intermediate and advanced group as compared to FI individuals in the two proficiency levels had similar performances. The significance of the difference between these proficiency levels was explored conducting two independent samples $t$-tests (Tables $5 \& 6$ ). The magnitude of the difference in the means was small (Eta squared=.042). Therefore, proficiency level did not have any significant effect on the performance of FD and FI participants in apology DCTs.

The findings were not in line with most of the studies mentioned in the literature. For example, Yaghoubi (1994) conducted a research aimed at examining whether, and to what extent, there was a relationship between FD/FI cognitive styles and foreign language proficiency of Iranian EFL students. The study revealed that FI learners outperformed FD ones in language classes, and that FI cognitive style was conducive to language learning. However, it must be noted 
that prior to conducting this study participants did not undergo any special treatment or have any instructions in pragmatics. Probably the context that the student brings to understand a message may differ among individuals because of their internal states and cognitive abilities. Therefore, the findings for the proficiency levels were not consistent with Fatemi et al. (2014), Khalili Sabet and Mohammadi (2013), Shalbafan (1996), and Salmani Nodoushan's (2006) view that learners' cognitive style (FD/FI) is crucial in benefitting from a specific teaching method.

The next research question to be explored was related to the three age groups. In the case of FD participants, a statistically significant difference was observed in the apology scores of three age groups (Tables $7 \& 8), F(7,247)=$ 4.376, $\mathrm{P}=0.010$. Similarly, the findings obtained by the analysis of the apology scores of FI participants revealed that there was a statistically significant difference between three age groups, $\mathrm{F}(7,391)=5.912, \mathrm{P}=0.000$. However, the FD/FI cognitive style did not have any significant effect on the performance of the same age group. For example, the EFL learners from 17 to 22 years old had similar performances, whether they were FD/FI. Analysis revealed that learners evaluated the appropriateness of linguistic strategies in response to the task. Supporting our findings based on what Kasper and Rose (2002) noted, the issue of age is not treated as a neuropsychological trait but as a social category. The status conferred to different age groups in the host society could have consequences for learners to develop their L2 pragmatic ability.

Considering gender, statistical analysis showed that females were more pragmatically mature socialized and outperformed males in being cautious and showing more sensitivity to the speech act situations. EFL students, due to their own sociolinguistic and sociocultural differences, have different ways of establishing an apologizing relationship with their counterparts. As already mentioned, in order to maintain the homogeneity of the two groups as far as gender was concerned, equalization was undertaken. Thus, numerical findings for the effect of gender on MCDCTs according to Table 10, showed that FD/FI cognitive styles had a significant effect on the performance of male $(t(45)=3.81, P=$ $0.000)$ and female $(t(45)=3.39, P=0.000)$ groups. These findings were in line with Tinajero and Paramo (1998), Haji Maibodi (2016), and Holmes (1995, 2008) who believed that women think apologies as being polite while men may avoid them where it is possible. Men will apologize only if it will cause offence. Differences in gender and age show an increase in EFL learners' development of a better command of the pragmalinguistic potential of lexical and syntactic devices (Haji Maibodi, 2016).

Pragmatic awareness has been described as important in the generation and negotiation of meaning. It gains importance when speakers evaluate context in their formulations of certain speech acts (Bergman \& Kasper, 1993). In class, discussions with the participants from the two groups that took place after the study showed how learners create and test different hypotheses about the nature of the target pragmatic structure. They confessed to evaluations, assessment, and adjustments made in accordance with the contextual variables of social power, social distance, and severity of offence. Our students knew "what to say but not how to say it."

\section{Pedagogical Implications}

This study has been driven mainly by pedagogical concerns and the findings have important implications for L2 pedagogy and teacher development. The results provide additional evidence that FI as compared to FD is related to L2 achievement especially in formal school settings. Language learners are more successful if they can recognize the type of cognitive style that is dominant in them. Though one type of cognitive style can be dominant in an individual, it does not mean that the other type does not exist in him. Very often students weave together their schoolwork lives with their personal lives. Learners are social beings with their own cultural values, beliefs, and worldview. Their cognitive styles and IDs are likely to influence how they present themselves in their L2 pragmatic behavior. Politeness is not only a general way of behaving but also an assessment about an individual in a particular situation.

However, appropriate instruction on L2 pragmatics must be included at all levels in the curriculum through adequate exposure, modeling, and corrective feedback. This will ensure that learners will not only understand the illocutionary meaning but they will also be exposed to the perlocutionary effects of a range of L2 pragmatic norms typically used and preferred by NSs of the language. Hence, Second Language Acquisition (SLA) theory needs to develop a more textured understanding of the relationship between the language learners and the social world. No doubt, education has been and will continue to be an important part of our life. Its crucial role in the development of human beings cannot be denied. However, compared with other areas, research in the area of cognitive development and pragmatic competence is not as impactful as expected to be. While some of the findings on interlanguage pragmatics may simply reflect the state of learners' lexical and syntactic knowledge, the issue becomes clearly a pragmalinguistic one when 
learners demonstrably know a particular lexical item or syntactic structure yet use it in a way that does not convey the intended illocutionary force or politeness value (Haji Maibodi et al., 2016).

\section{Conclusion}

Overall findings showed that although learners may not all use the same type of language or strategy to express their feelings but there was a strong interaction between cognitive styles and learners knowledge of what to say and how to say according to their IDs. The learning and use of a language other than the L1 is bound to have an impact on the person as a whole. The semantic content of lexical items depends on how speakers of a language categorize their experiences (Haji Maibodi et al., 2016). The novelty offered to the keen EFL/ESL reader is that there are no fixed rules to acquire pragmatic competence. If competence (Chomsky, 1965) is taken as underlying knowledge and nonobservable ability, an issue of "idealized speaker-hearer"; the findings show that it is not so. Individual differences can play an important role in this concrete manifestation of language use. Findings showed that students not only produce utterances based on created intentions but they also do not merely repeat a sentence explicitly identified by their instruction. Interestingly, findings from the current study lead to the conclusion that Iranian non-native speakers' pragmatic norms may not be completely based on Western patterns and norms of social interaction. Largely, these interactions are based on sociocultural and socio-psychological factors that govern patterns of behavior (Haji Maibodi et al., 2016). Apparently, a great deal of what we want to communicate is determined by our IDs and social relationships, and students with different types of cognitive styles may need different instructional strategies to suit their information processing needs and learner preferences.

\section{References}

Afghari, A. (2007). A sociopragmatic study of apology speech act realization patterns in Persian. Speech Communication, 49(3), 177-185. doi:10.1016/j.specom.2007.01.003

Ahmadi, A. (2002). On the relationship between field dependence independence and the use of listening comprehension strategies by Iranian EFL students (case study: female English majors in Shiraz). Unpublished Master's Thesis. Shiraz University, Iran.

Bachman, L. F., \& Palmer, A. S. (2010). Language assessment in practice. Oxford: Oxford University Press.

Bardovi-Harlig, K., \& Bastos, M. T. (2011). Proficiency, length of stay, and intensity of interaction, and the acquisition of conventional expressions in L2 pragmatics. Intercultural Pragmatics, 8(3), 347-384. doi.org/10.1515/iprg.2011.017

Bayat, N. (2013). A study on the use of speech acts. Procedia-Social and Behavioral Sciences, 70, $213-221$. Retrieved from: www.sciencedirect.com

Bergman, M. L., \& Kasper, G. (1993). Perception and performance in native and nonnative apology. In G. Kasper, \& S. Blum-Kulka (Eds.), Interlanguage pragmatics (pp. 82-107). New York, NY: Oxford University Press.

Biook, B., \& Fathi, M. (2009). The relationship between reading performance and field dependence/independence cognitive styles. Journal of Teaching English as a Foreign Language and Literature, 1(1), 49-62. https://www.sid.ir/en/journal/ViewPaper.aspx?id=201535

Birjandi, P., \& Rezaei, S. (2010). Developing a multiple-choice discourse completion test of interlanguage pragmatics for Iranian EFL learners. ILI Language Teaching Journal (Special Issue: Proceedings of the First Conference on ELT in the Islamic World), 6(1, 2), 43-58.

Bosacki, S., Innerd, W., \& Towson, S. (1997). Field independence-dependence and self-esteem in preadolescents: Does gender make a difference? Journal of Youth and Adolescence, 26(60), 691-704. https://doi.org/10.1023/A:1022396625462

Brown, D. (2007). Principles of language teaching and learning. White Plains, NY: Pearson Longman.

Carroll, F., \& Sapon, E. (1988). Sex differences in English language acculturation and learning strategies among Vietnamese adults aged 40 and over in the United States. Sex Roles, 19, 747-758.

Chomsky, N. (1965). Aspects of the theory of syntax. Cambridge, Massachusetts, Massachusetts Institute of Technology Press: 251p. 
Davies, K. A., \& Skilton-Sylvester, E. (2004). Looking back, taking stock, moving forward: Investigating gender in TESOL. TESOL Quarterly, 38(3), 381-404. doi.org/10.2307/3588346

Ellis, R. (2008). The study of second language acquisition. Oxford: Oxford University Press.

Fajen, A. (1999). Language learning strategies used by Japanese university students. RELC Journal, $30(2), 101-113$. doi.org/10.1177/003368829903000206

Fatemi, A. H., Vahedi, V. S., \& Seyyedrezaie, S. Z. (2014). The effects of top-down/bottom-up processing and fielddependent/field-independent cognitive style on Iranian EFL learners' reading comprehension. Theory and Practice in Language Studies, 4(4), 686-693. doi:10.4304/tpls.4.4.686-693

Griffin, T., \& Franklins, D. (1996). Can strategy instruction improve listening comprehension? Foreign Language Annals, 29(3), 331-342. doi: 10.1111/j.1944-9720.1996.tb01246.x

Haji Maibodi. A. (2016). Investigating the effects of individual differences on the speech act of apology in institutional discourse. Journal of Modern Research in English Language Studies, 3(2), 71-94. http://jmrels.journals.ikiu.ac.ir/article_955.html

Haji Maibodi, A., Fazilatfar, A. M., \& Allami, H. (2016). Exploring subjectivity in verbal reports of Iranian EFL learners in institutional discourse. International Journal of Applied Linguistics \& English Literature, 5(5), 252263. doi:10.7575/aiac.ijalel.v.5n.5p.252

Hansen, J. R., \& Stansfield, C. (1981). The relationship of field dependent/independent cognitive styles to foreign language. Language Learning, 31(2), 349-367. doi: 10.1111/j.1467-1770.1981.tb01389.x

Hashemian, M., \& Farhang-Ju, M. (2018). Effects of metalinguistic feedback on grammatical accuracy of Iranian field (in) dependent L2 learners' writing ability. Journal of Research in Applied Linguistics, 9(2), 141-161. doi:10.22055/rals.2018.13797

Hashemian, M., Jafarpour, A., \& Adibpour, M. (2015). Exploring relationships between field (In) dependence, multiple intelligences, and L2 reading performance among Iranian L2 learners. Journal of Research in Applied Linguistics, 6(1), 40-63. doi: 10.22055/rals.2015.11259

Holmes, J. (1995). Women, men, and politeness. London: Longman Group.

Holmes, J. (2008). An introduction to sociolinguistics. (3 ${ }^{\text {rd }}$ Ed.), (pp.164-168). England, UK: Pearson, Longman Group.

Ishihara, N., \& Cohen. A. D. (2010). Learners' pragmatics: potential causes of divergence. In N. Ishihara \& A. D. Cohen (Eds.), Teaching and learning pragmatics: Where language and culture meet (pp. 75-96). Harlow: Longman.

Kasper, G., \& Rose, K. (2002). The role of instruction in learning second language pragmatics. Language Learning, 52(1), 237-273. https://doi.org/10.1111/j.1467-1770.2002.tb00028.x

Kasper, G., \& Schmidt, R. (1996). Developmental issues in interlanguage pragmatics. Studies in Second Language Acquisition, 18(2), 149-169. doi: https://doi.org/10.1017/S0272263100014868

Khalili Sabet, M., \& Mohamadi, S. H. (2013). The relationship between field independence/dependence styles and reading comprehension abilities of EFL readers. Unpublished Master dissertation. Iran.

Khodadady, E., Bagheri, N., \& Charbgoo, Z. (2016). Primary school students' cognitive styles and their achievement in English as a foreign language. Journal of Language Teaching and Research, 7(5), 851-858. doi: http://dx.doi.org/10.17507/jltr.0705.04

Khodadady, E., \& Zeynali, S. (2012). Field-dependence/independence cognitive style and performance on the IELTS listening comprehension. International Journal of Linguistics, 4(3), 622-635. doi:10.5296/ij1.v4i3.2389

Kuriscak, L. (2010). The effect of individual-level variables on speech act performance. In A. Martíneze-Flor \& E. Usó-Juan (Eds.), Speech act performance: Theoretical, empirical and methodological issues (pp. 23-39). Amsterdam: John Benjamins. 
Luk, S. C. (2002). The relationship between cognitive styles and academic achievement. British Journal of Educational Technology, 29(2), 137-147. https://doi.org/10.1111/1467-8535.00055

Marinova-Todd, S. H., Bradford, M. D., \& Snow, C. E. (2000). Three misconceptions about age and learning. TESOL Quarterly, 34(1), 9-34. doi: 10.2307/3588095 http://links.jstor.org/sici?sici=00398322\%28200021\%2934\%3A1\%3C9\%3ATMAAAL\%3E2.0.CO\%3B2-M

Nilforooshan, N., \& Afghari, A. (2007). The effect of field dependence-independence as a source of variation in EFL learners' writing performance. Iranian Journal of Language Studies (IJLS), 1(2), 58-70. http://journaldatabase.info/articles/effect_field_dependence-independence.html

Reid, J. M. (2002). Learning styles in the ESL/EFL classroom. U.S.A., Brooks Cole Thomson Learning.

Rickards, J. P., Fajen, B. R., Sullivan, J. F., \& Gillespie, G. (1997). Signaling, note taking, and field independencedependence in text comprehension and recall. Journal of Educational Psychology, 89(3), 508-517. https://doi.org/10.1037/0022-0663.89.3.508

Rostampour, M., \& Niroomand, S. M. (2014). Field dependence/independence cognitive styles: Are they significant at different levels of vocabulary knowledge? International Journal of Education \& Literacy Studies, 2(1), 5257. doi:10.7575/aiac.ijels.v.2n.1p.52

Sabaté i Dalmau, M., \& Curelli Gotor, H. (2007). From "sorry very much" to "I'm ever so sorry": Acquisitional patterns in L2 apologies by Catalan learners of English. Intercultural Pragmatics, 4(2), 287-315. doi: 10.1515/IP.2007.014

Salmani-Nodoushan, M. A. (2006). Does field independence relate to performance on communicative language tests? Manager's Journal of Educational Technology, 3(3), 79-85. doi: 10.26634/jet.3.3.716

Salmani-Nodoushan, M. A (2007). Is field dependence or Independence a predicator of EFL reading performance? TESL Canada Journal, 24(2), 82-108. https://doi.org/10.18806/tesl.v24i2.140

Shalbafan, K. (1996). On the role field dependence/field independence in Iranian EFL learners' writing ability. Unpublished master's thesis. Tehran, Iran: University of Tehran.

Sheorey, R., \& Mokhtari, K. (2001). Differences in the metacognitive awareness of reading strategies among native and non-native readers. System, 29(4), 431-449. https://doi.org/10.1016/S0346-251X(01)00039-2

Taguchi, N. (2013). Individual differences and development of speech act production. Applied Research on English Language, 2(2), 1-16. https://www.sid.ir/En/Journal/ViewPaper.aspx?ID=329224

Takahashi, S. (2005). Pragmalinguistic awareness: Is it related to motivation and proficiency? Applied Linguistics, 26(1), 90-120. https://doi.org/10.1093/applin/amh040

Tinajero, C., \& Paramo, M. F. (1998). Field dependence-independence cognitive style and academic achievement: A review of research and theory. European Journal of Psychology of Education, 13, $227-251$. https://doi.org/10.1007/BF03173091

Trosborg, A. (1995). Interlanguage pragmatics: Requests, complaints and apologies. Berlin/New York: Mouton de Gruyter.

Witkin, H. A., Moore, C. A., Goodenough, D. R., \& Cox, P. W. (1977). Field- dependent and field-independent cognitive styles and their educational implications. Review of Educational Research, 47(1), 1-64. doi: 10.2307/1169967 https://www.jstor.org/stable/1169967

Yaghoubi, R. (1994). The relationship between field-independent/field-dependent cognitive style Persian students and their English language proficiency. Unpublished master's thesis, Allameh Tabatabaii University, Iran. 


\section{Appendix: Multiple Choice Discourse Completion Tasks (MCDCTs)}

1. You borrowed a book from your teacher but you accidentally spilled a cup of coffee all over it. You return it to the teacher. How do you apologize to him/her?

The Teacher: (very angry) I can't believe it. This was the only copy I had.

You:

a. Sorry, it was an accident, chill out.

b. I am deeply sorry. Please allow me to replace the copy.

c. I'm desperately sorry but accidents happen, you know?

d. Oh God! I couldn't help it.

2. Suppose that the teacher is teaching and you are talking to your classmate. The teacher gets angry with you. How do you express your apology?

The Teacher: Don't you think it is impolite to speak while I am teaching?

You:

a. I beg your pardon. I won't let it happen again.

b. OK! OK! Alright. I guess you're right.

c. Excuse me. I didn't mean to interrupt you.

d. I know, but I had something very important to tell him/her. 